\title{
Neuronal voltage-gated ion channels are genetic modifiers of generalized epilepsy with febrile seizures plus
}

\author{
Nicole A. Hawkins ${ }^{a, 1}$, Melinda S. Martin ${ }^{c, 1}$, Wayne N. Frankeld, Jennifer A. Kearney ${ }^{b},{ }^{*}$, and \\ Andrew Escayg ${ }^{\mathrm{C}}$ \\ a Neuroscience Graduate Program, Vanderbilt University Medical Center, Nashville, TN 37232, \\ USA \\ b Division of Genetic Medicine, Department of Medicine, Vanderbilt University Medical Center, \\ Nashville, TN 37232, USA \\ c Department of Human Genetics, Emory University, Atlanta, GA 30322, USA \\ d The Jackson Laboratory, 600 Main Street, Bar Harbor, ME 04609, USA
}

\begin{abstract}
Mutations in the neuronal voltage-gated sodium channel genes SCN1A and SCN2A are associated with inherited epilepsies, including genetic epilepsy with febrile seizures plus (GEFS+) and Dravet syndrome (severe myoclonic epilepsy of infancy). The clinical presentation and severity of these epilepsies vary widely, even in people with the same mutation, suggesting the action of environmental or genetic modifiers. To gain support for the hypothesis that genetic modifiers can influence clinical presentation in patients with SCNIA-derived GEFS+, we used mouse models to study the effect of combining the human GEFS+ mutation SCN1A-R1648H with SCN2A, KCNQ2, and SCN8A mutations. Knock-in mice heterozygous for the R1648H mutation $\left(S c n 1 a^{R H /+}\right)$ have decreased thresholds to induced seizures and infrequent spontaneous seizures, whereas homozygotes display spontaneous seizures and premature lethality. Scn $2 a^{Q 54}$ transgenic mice have a mutation in $S c n 2 a$ that results in spontaneous, adult-onset partial motor seizures, and mice carrying the Kcnq2-V182M mutation exhibit increased susceptibility to induced seizures, and rare spontaneous seizures as adults. Combining the $S c n 1 a-\mathrm{R} 1648 \mathrm{H}$ allele with either $S c n 2 a^{Q 54}$ or $K c n q 2^{\mathrm{V} 182 \mathrm{M} /+}$ results in early-onset, generalized tonic-clonic seizures and juvenile lethality in double heterozygous mice. In contrast, $S c n 8 a$ mutants exhibit increased resistance to induced seizures. Combining the Scnla-R1648H and Scn8a-med-jo alleles restores normal thresholds to flurothyl-induced seizures in $S c n 1 a^{R H /+}$ heterozygotes and improved survival of $S c n 1 a^{R H / R H}$ homozygotes. Our results demonstrate that variants in $S c n 2 a, K c n q 2$, and $S c n 8 a$ can dramatically influence the phenotype of mice carrying the Scnla-R1648H mutation and suggest that ion channel variants may contribute to the clinical variation seen in patients with monogenic epilepsy.
\end{abstract}

\footnotetext{
*To whom correspondence should be addressed: Jennifer Kearney, 529 Light Hall, 2215 Garland Ave, Nashville, TN 37064, Phone: 615-936-8544, jennifer.kearney@vanderbilt.edu.

${ }^{1}$ These authors contributed equally to this work. CONFLICT OF INTEREST STATEMENT

The mouse model of GEFS+ described in this manuscript has been licensed to Allergan. The terms of this arrangement have been reviewed and approved by Emory University in accordance with its conflict of interest policy.

Publisher's Disclaimer: This is a PDF file of an unedited manuscript that has been accepted for publication. As a service to our customers we are providing this early version of the manuscript. The manuscript will undergo copyediting, typesetting, and review of the resulting proof before it is published in its final citable form. Please note that during the production process errors may be discovered which could affect the content, and all legal disclaimers that apply to the journal pertain.
} 


\section{INTRODUCTION}

During the past 15 years, research has revealed several genes underlying rare monogenic forms of idiopathic generalized epilepsy (IGE); however, there has been less progress towards the identification of genes involved in the more common, genetically complex forms of IGE (Greenberg and Pal, 2007; Heron et al, 2007; Tan et al, 2006). Many of the genes now known to cause monogenic forms of epilepsy encode neuronal ion channel subunits, including voltage-gated sodium and potassium channels. Mutations in the voltagegated sodium channels $S C N 1 A, S C N 2 A$, and $S C N 1 B$ result in genetic (generalized) epilepsy with febrile seizures plus (GEFS+) (Escayg et al, 2000; Sugawara et al, 2001; Wallace et al, 1998). We recently generated a mouse model of GEFS+ by introducing the human SCN1A$\mathrm{R} 1648 \mathrm{H}$ GEFS+ mutation, which was identified in a large pedigree with 13 affected members, into the orthologous mouse Scnla gene (Martin et al, 2010).

Scnla $a^{R 1648 H /+}$ heterozygous mutants $\left(S c n 1 a^{R H /+}\right)$ display a normal lifespan, reduced thresholds to flurothyl- and hyperthermia-induced seizures, and infrequent spontaneous generalized seizures as adults (Martin et al, 2010). Scnla $a^{R H / R H}$ homozygous mice exhibit spontaneous generalized seizures and have an average lifespan of 18.5 days. Cortical interneurons from $S c n l a^{R H /+}$ and $S c n l a^{R H / R H}$ mice display slowed recovery from inactivation, increased use-dependence, and a reduced ability to fire action potentials. These electrophysiological abnormalities are predicted to reduce the level of GABAergic inhibition, providing a mechanism for seizure generation (Martin et al, 2010).

Mutations in the voltage-gated sodium channel SCN2A have also been associated with human epilepsy syndromes, including GEFS+ and benign familial neonatal-infantile seizures (BFNIS) (Meisler and Kearney, 2005). The transgenic mouse model Scn2a ${ }^{Q 54}$ has a gain-of-function mutation in $S c n 2 a$ and a progressive epilepsy phenotype characterized by partial motor seizures that begin in the second month of life, followed by the development of secondary generalized seizures and a reduced lifespan. Hippocampal pyramidal neurons from $\operatorname{Scn} 2 a^{Q 54}$ mice exhibit increased persistent sodium current (Kearney et al, 2001).

Mutations in the voltage-gated potassium channel genes $K C N Q 2$ and $K C N Q 3$ are associated with benign familial neonatal convulsions (BFNC), characterized by clusters of seizures in the first days of life and remission within the first year (Biervert et al, 1998; Charlier et al, 1998; Singh et al, 1998). $\mathrm{K}_{\mathrm{v}} 7.2$ and $\mathrm{K}_{\mathrm{v}} 7.3$, encoded respectively by $K C N Q 2$ and $K C N Q 3$, heterodimerize to form a slowly activating and inactivating voltage-gated potassium channel that generates the M-current, which is important in controlling repetitive firing upon strong excitatory stimulation (Cooper and Jan, 2003; Delmas and Brown, 2005). The Kcnq2 $2^{\text {Nmfl } 134}$ line was generated by ethylnitrosourea (ENU) mutagenesis and carries the amino acid substitution V182M in the third transmembrane segment of Kcnq2. Kcnq2 $2^{V 182 M /+}$ heterozygous mutants $\left(K c n q 2^{V M /+}\right)$ exhibit reduced thresholds for minimal clonic seizures and rare spontaneous seizures as adults; however, they have a normal lifespan (Kearney et al, 2006). We previously showed genetic interaction between $S c n 2 a$ and Kcnq2 in mice (Kearney et al, 2006).

SCN8A mutations are associated with ataxia and behavioral abnormalities in humans and movement disorders in mice. Mice homozygous for the $S c n 8 a^{\text {med-jo }}$ missense mutation exhibit tremor and cerebellar ataxia. Although heterozygous mutants have no visible abnormalities, they do have spontaneous spike-wave discharges characteristic of nonconvulsive, absence seizures (Dick et al, 1986; Kohrman et al, 1996; Papale et al, 2009; Sidman et al, 1979). We recently found that heterozygous Scn8a med-jo/+ mutants and heterozygous $S c n 8 a^{m e d /+}$ mutants, that carry a loss-of-function mutation, were more resistant to flurothyl- and kainic acid-induced seizures. We also showed that the Scn $8 a^{\text {med-jo }}$ 
allele could rescue the reduced seizure threshold and premature lethality of heterozygous Scnla knockout mice, suggesting that $S c n 8 a$ may play an important role in the excitatory circuits that influence convulsive seizure thresholds (Martin et al, 2007).

Unrelated individuals with GEFS+ exhibit a wide range of epilepsy subtypes and severities that may reflect, in part, the relative effect of different SCNIA mutations on channel function. Similar variability is also seen between affected family members who carry the same SCN1A mutation (Fujiwara, 2006; Singh et al, 2001). This suggests that in addition to the primary mutation, the clinical manifestation of epilepsy can be influenced by other factors such as stochastic events during development, environmental influences or genetic modifiers. Mouse models with sodium channel mutations exhibit variable phenotypes depending on the genetic background, supporting a role for genetic modifiers (Bergren et al, 2005; Kearney et al, 2006; Ogiwara et al, 2007; Yu et al, 2006). Based on these observations, we hypothesize that genetic modifier loci may contribute to the variable clinical presentation observed in GEFS+.

To test the hypothesis that genetic modifiers can contribute to GEFS+ variability, we examined the effect of mutations in $S c n 2 a, K c n q 2$, and $S c n 8 a$ on the epilepsy phenotype of the Scn1 $a^{R 1648 H}$ mouse model. Here we demonstrate that mutations in Scn2a and Kcnq2 exacerbate the phenotype, whereas altered $S c n 8 a$ function ameliorates it. Our results provide support for genetic modification as one mechanism by which the clinical presentation of GEFS + can be altered underscoring that neuronal excitability is influenced by the net activity of ion channels.

\section{MATERIALS AND METHODS}

\section{Animals}

Scn $1 a^{R 1648 H}$ mice were generated as previously described (Martin et al, 2010). Scnla $a^{R 1648 H}$ mice, on the 129S6.C57BL/6J $\left(\mathrm{N}_{2-3}\right)$ background, were used for mating with $K c n q 2^{V M /+}$ and Scn $8 a^{\text {med-jo/+ }}$ mice. Scnla $a^{R 1648 H}$ mice on the 129 S6/SvEvTac background were used for mating with $S c n 2 a^{Q 54}$ mice. The $K c n q 2^{V 182 M}$ mice were generated at The Jackson Laboratory by ENU mutagenesis (http://nmf.jax.org). Kcnq2 $2^{V M /+}$ heterozygous mutants are maintained by continued backcrossing to C57BL/6J. Scn2a $a^{254}$ transgenic mice congenic on the C57BL/6J background were established as described (Bergren et al, 2005) and are maintained by continued backcrossing of hemizygous transgenic males to C57BL/6J females. C57BL/6J-Scn $8 a^{m e d-j o} / \mathrm{J}$ mice were purchased from The Jackson Laboratory and

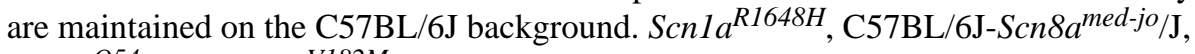
$S c n 2 a^{Q 54}$, and $K c n q 2^{V 182 M}$ mice were genotyped as previously described (Kearney et al, 2001; Kearney et al, 2006; Martin et al, 2007; Martin et al, 2010).

\section{Generation of double mutant mice}

Double heterozygous mutants were generated by crossing $S c n 1 a^{R H /+}$ females with $K c n q 2^{V M /+}, S c n 8 a^{m e d-j o /+}$, or Scn $2 a^{Q 54}$ males. Scn1a ${ }^{R H / R H} ; S c n 8 a^{\text {med-jo/+ }}$ mutants were generated by crossing $S c n 1 a^{R H /+} ; S c n 8 a^{m e d-j o /+}$ males with $S c n l a^{R H /+}$ females. All double mutants were obtained at expected Mendelian ratios. Littermates were used for all experiments to minimize variation due to differences in genetic background. Mice were housed in pathogen-free mouse facilities with 12-h light/dark cycles. Food and water were available ad libitum. All experimental protocols were approved by the Emory University and Vanderbilt University IACUC committees. 


\section{Flurothyl seizure induction}

Mice between 8 and 12 weeks of age were placed in a clear Plexiglas chamber, and flurothyl (2,2,2-trifluroethylether) (Sigma-Aldrich) was slowly introduced into the chamber via a syringe pump at a rate of $20 \mu \mathrm{l} / \mathrm{min}$ and allowed to volatilize. Seizure thresholds were determined by measuring latency to the first MJ and GTCS. The MJ is the first observable behavioral response and is characterized by a brief jerk of the shoulders and/or neck. The GTCS is characterized by convulsions of the entire body and a loss of posture. Data from males and females were analyzed separately. No sex differences were observed; therefore, data from both sexes were combined. Statistical analysis between genotypes was performed using one-way analysis of variance (ANOVA) followed by Fisher's post-hoc test.

\section{Video-ECoG monitoring}

Mice were implanted with prefabricated headmounts (Pinnacle Technology, Inc.) for videoECoG monitoring. Briefly, mice were anesthetized with isoflurane and placed in a stereotaxic frame (Kopf), and headmounts were attached to the skull with four stainless steel screws that serve as cortical surface electrodes. Headmounts were positioned $0-0.5 \mathrm{~mm}$ posterior to lambda. The anterior screw electrodes were $0.5-1 \mathrm{~mm}$ posterior to bregma and 1 $\mathrm{mm}$ lateral from the midline. The posterior screws were $4.5-5 \mathrm{~mm}$ posterior to bregma. After $\geq 24$ hours of recovery, mice were placed in a Plexiglas bowl ( $14^{\prime \prime} \mathrm{h} \times 16^{\prime \prime}$ diameter), and ECoG data were collected from freely moving mice. Digitized data were acquired and analyzed with Sirenia software (Pinnacle Technology, Inc.) along with contemporaneous video recordings. Epileptiform activity was scored manually.

\section{RESULTS}

\section{Scn2a ${ }^{Q 54}$ and $K c n q 2^{V 182 M}$ alleles reduce the lifespan of Scn1a ${ }^{R H /+}$ mutants}

To model the effect of inheriting mutations in the Scn1a and Scn2a sodium channel genes, we generated $S c n 1 a^{R H /+} ; S c n 2 a^{Q 54}$ double mutants. Beginning at P16, Scn1a ${ }^{R H /+} ; S c n 2 a^{Q 54}$ double mutants exhibit spontaneous partial motor seizures and generalized tonic-clonic seizures (GTCS). In 137 hours of ECoG recording, we observed 25 GTCS and 11 partial motor seizures (Table 1; Fig. 2). Generalized seizures lasted 45-100 seconds, during which time mice experienced repetitive jerking of all four limbs and neck, running and jumping, and tail clonus (Supplementary Video 1). These seizures often ended with tonic hindlimb extension, indicative of a severe seizure. During ECoG recording, we observed that two Scn $1 a^{R H /+} ; \operatorname{Scn} 2 a^{Q 54}$ mice had severe seizures with hindlimb extension followed by death. Partial motor seizures lasted $<10$ seconds, and were characterized by forelimb clonus (Supplementary Video 2). Scn $2 a^{Q 54}$ littermates displayed a similar number of partial motor seizures; however, GTCS were rare, with only one observed during 168 hours of ECoG recordings (Table 1). We saw no seizures in Scnla $a^{R H /+}$ littermates (Table 1, Fig. 2), as was expected from previous monitoring of 3-5 month old $S c n l a^{R H /+}$ mice that detected spontaneous seizures with a low average frequency of one seizure per 64 hours of recording (Martin et al, 2010). Sporadic death of $S c n 1 a^{R H /+} ; S c n 2 a^{Q 54}$ double mutants began to occur at P16, with $100 \%$ mortality by P24 (Fig. 1).

To model the effect of inheriting mutations in Kcnq2 and Scnla, we generated Scn $1 a^{R H /+} ; K c n q 2^{V M /+}$ double heterozygous mutants. At P16, Scn $1 a^{R H /+} ; K c n q 2^{V M /+}$ mice began to display spontaneous generalized seizures. In 330 hours of ECoG recording, we observed 87 myoclonic jerks, four GTCS, and one partial motor seizure in the double heterozygous mutants (Table 1; Fig. 2). During a generalized seizure, the mice typically experienced repetitive jerking of all four limbs and neck, running and jumping, and tail clonus (Supplementary Video 3). Generalized seizures were periodically followed by tonic extension of the hindlimbs. During ECoG recording, we observed that two 
Scnla $a^{R H /+} ; K c n q 2^{V M /+}$ mice had severe seizures with hindlimb extension followed by death. We observed no epileptiform events in the $S c n 1 a^{R H /+}$ or Kcnq $2^{V M /+}$ littermates. At P19, sporadic death of the double heterozygous mice began to occur, and there was $42 \%$ mortality by P25 (Fig. 1), demonstrating the ability of the $K c n q 2^{V 182 M}$ allele to exacerbate the phenotype of the $S c n 1 a^{R H /+}$ mice. Interestingly, $47 \%$ of double heterozygous mutants survived for more than 100 days (Fig. 1).

\section{Scn8a dysfunction restores normal seizure thresholds in Scn1a $\mathrm{RH}^{\mathrm{H}+}$ mutants}

We previously demonstrated that two heterozygous Scn8a mutants, Scn $8 a^{\text {med-jo/+ }}$ and Scn $8 a^{m e d /+}$, exhibit increased resistance to flurothyl- and kainic acid-induced seizures (Martin et al, 2007). In contrast, $S c n l a^{R H /+}$ mutants have reduced thresholds to flurothylinduced GTCS (Martin et al, 2010). To investigate whether the Scn8 $a^{\text {med-jo }}$ allele could alter convulsive seizure thresholds in $S c n 1 a^{R H /+}$ mice, we generated double heterozygous mutants harboring both mutations. Thresholds to flurothyl-induced seizures were compared between $S c n 1 a^{R H /} ; S c n 8 a^{\text {med-jo/+ }}$ double heterozygotes, single heterozygotes, and wild-type (WT) littermates.

In agreement with our previous observations (Martin et al, 2007; Martin et al, 2010), when compared to WT littermates, the average latency to flurothyl-induced GTCS in Scn $8 a^{\text {med-jo/+ }}$ mutants was $30 \%$ longer while a $21 \%$ reduction was observed in $S c n 1 a^{R H /+}$ mutants (Fig. 3). For the $S c n 1 a^{R H /+} ; S c n 8 a^{m e d-j o /+}$ double mutants, the average latency to GTCS was 50\% longer when compared to the Scn $1 a^{R H /+}$ mutants (Fig. 3). One-way ANOVA detected an effect of genotype $\left(\mathrm{F}_{(3,35)}=9.858, \mathrm{p} \leq 0.001\right)$. Post hoc analysis demonstrated that when compared to WT littermates, the increased latency to the GTCS shown by $S c n 8 a^{\text {med-jo/+ }}$ mutants as well as the decreased latency to the GTCS observed in Scnla $a^{R H /+}$ mutants were statistically significant ( $\mathrm{p}<0.05$ for both comparisons, Fisher). In addition, the increased latency to GTCS observed in Scn $1 a^{R H /+} ; S c n 8 a^{\text {med-jo/+ }}$ double mutants was statistically significant when compared to $S c n 1 a^{R H /+}$ mutants, but was not statistically different from WT littermates ( $\mathrm{p} \leq 0.001$ and $\mathrm{p} \geq 0.05$, respectively; Fisher). These results demonstrate that seizure thresholds can be restored to more normal levels in $S c n 1 a^{R H /+}$ mice by altering the function of $S c n 8 a$.

\section{Scn8a $a^{\text {med-jo }}$ mutation prolongs the lifespan of $S c n 1 a^{R H / R H}$ mutants}

To determine whether the presence of the $S c n 8 a^{\text {med-jo }}$ allele could improve the survival of homozygous $S c n l a^{R H / R H}$ mice, we compared the lifespans of $S c n 1 a^{R H / R H}$ and $S c n 1 a^{R H / R H} ; S c n 8 a^{m e d-j o /+}$ littermates. Similar to previous observations, $S c n l a^{R H / R H}$ mutants exhibited 50\% mortality by P19.5 and 100\% lethality by P25 (Fig. 4) (Martin et al, 2010). In contrast, only $25 \%$ mortality was observed for $S c n 1 a^{R H / R H} ; S c n 8 a^{\text {med-jo/+ }}$ mice at P25 (P = $1.8 \times 10^{-4}$ ), and $47 \%$ of these mutants survived for over 100 days (Fig. 4).

\section{DISCUSSION}

One feature of GEFS+ is the wide range of seizure types and severities frequently seen among family members with the same SCN1A mutation (Fujiwara, 2006; Meisler and Kearney, 2005; Singh et al, 2001). Based on these observations, we hypothesized that the variable clinical presentation in GEFS+ is due, in part, to contributions from additional genetic modifiers.

Even though it is well recognized that genetic modifiers can influence the clinical presentation of a disorder, we know of relatively few human modifier genes. Cystic fibrosis (CF) represents one good example of a monogenic human disease with a known genetic modifier. CF results from recessive mutations in CFTR, a cAMP-dependent chloride 
channel (Riordan et al, 1989). Multiple studies have shown a significant association between two transforming growth factor- $\beta$ (TGF- $\beta$ ) polymorphic variants and lung disease severity in CF (Arkwright et al, 2000; Drumm and Collins, 1993). TGF- $\beta$ is an inflammatory cytokine and directly inhibits CFTR function (Howe et al, 2004). As a result, polymorphisms that increase circulating TGF- $\beta$ levels are more common in patients with severe lung disease.

Although genetic interactions have been difficult to demonstrate in epilepsy patients, model organisms can help in the search for genetic modifiers of seizure severity. We previously demonstrated that mutations in other ion channels could modify spontaneous seizure activity and the lifespans of $S c n 1 a^{+/-}$and $S c n 2 a^{Q 54}$ mutants. Moreover, in the presence of the Scn $8 a^{\text {med-jo }}$ allele, the severe seizure phenotype of Scnlat $a^{+-}$mice is dramatically ameliorated (Martin et al, 2007). In contrast, the Kcnq2 mutations V182M and Szt1 exacerbate the epilepsy phenotype of $S c n 2 a^{Q 54}$ transgenic mice (Kearney et al, 2006).

Here we demonstrate that $S c n 2 a, K c n q 2$, and $S c n 8 a$ mutant alleles can modify the phenotype of $S c n 1 a^{R 1648 H}$ mice, supporting genetic modification as one mechanism by which the clinical presentation of GEFS + can be altered. The genetic interactions between these ion channels imply that variants within $S c n 2 a, K c n q 2$, and possibly $K c n q 3$, may exacerbate the clinical presentation of GEFS+, shifting it to a more severe part of the GEFS+ spectrum. As previously observed with $S c n l a^{+/-}$mutants (Martin et al, 2007), the $S c n 8 a^{\text {med-jo }}$ allele could rescue the increased susceptibility to flurothyl-induced GTCS in $S c n 1 a^{R H /+}$ mice by raising seizure thresholds to a level comparable to WT littermates. In addition, while $S c n l a^{R H / R H}$ mutants do not survive more than 26 days, $47 \%$ of $S c n 1 a^{R H / R H} ; S c n 8 a^{\text {med-jo/+ }}$ mutants were still alive after 100 days. These results demonstrate that altered $S c n 8 a$ function is capable of compensating for abnormalities in neuronal excitability caused by Scnla mutations. Furthermore, these results suggest that selective blocking of Scn8a may be similarly protective in patients with epilepsy. Interestingly, although $S c n 8 a^{\text {med-jo/+ }}$ heterozygotes have increased resistance against convulsive seizures, we recently reported that they do have spontaneous absence seizures, characterized by hypersynchrony of the thalamocortical system (Papale et al, 2009). This underscores the idea that the net effect of sodium channel dysfunction in different neuronal circuits is highly dependent on the channel composition and synaptic function within each circuit.

In contrast, whereas $S c n 1 a^{R H /+}$ mice have infrequent, adult-onset generalized seizures, the presence of either the $S c n 2 a^{Q 54}$ or Kcnq2 ${ }^{V 182 M}$ alleles results in severe, juvenile-onset generalized seizures and a shortened lifespan. Recordings of neurons isolated from Scnla mutant mice suggest that there is decreased GABAergic neurotransmission in the hippocampus and cortex (Martin et al, 2010; Ogiwara et al, 2007; Yu et al, 2006). In the Scn $1 a^{R H /+} ;$ Scn $2 a^{Q 54}$ double mutants, the combination of increased excitability of pyramidal neurons due to the $S c n 2 a$ mutation and decreased inhibition from the Scnla mutation results in severe generalized seizures and lethality. Reduced GABAergic inhibition may prevent localized seizure termination, resulting in secondary generalization of seizures and a more severe phenotype. Similarly, it has been demonstrated that loss of M-current in Kcnq2 mutants results in hyperexcitability of hippocampal pyramidal CA1 neurons, which in combination with reduced GABAergic inhibition may permit secondary generalization of seizures in double $S c n 1 a^{R H /+} ; K c n q 2^{V M /+}$ mutants (Otto et al, 2006; Singh et al, 2008). Alternatively, because these genes have widespread expression in the brain, it is possible that the severe phenotype observed in double mutant mice may be the result of primary generalized seizures.

Given that the $S c n 1 a^{R H / R H} ; S c n 8 a^{m e d-j o /+}$ and $S c n 1 a^{R H /+} ; K c n q 2^{V M /+}$ compound mutants are on mixed genetic backgrounds, the $47 \%$ and $42 \%$ survival rates observed raises the possibility that genetic variants which differ between the C57BL/6J and 129S6/SvEvTac 
inbred strains may influence disease severity. Alternatively, the increased mortality between P20 to P40 in compound heterozygotes may reflect a more vulnerable juvenile stage due to ongoing maturation processes in the developing brain. In humans KCNQ2 dysfunction leads to BFNC, an epilepsy disorder affecting the neonate which typically remits by one year of age. The spontaneous remission of BFNC appears to correlate with brain maturation (Cooper and Jan 2003). However, it is also plausible that the observed survival rates are due to stochastic events.

Together with our previous study analyzing the $S c n 2 a^{Q 54} ; K c n q 2^{V M /+}$ mice, our observations from $S c n 1 a^{R H /+} ; K c n q 2^{V M /+}$ mutants illustrate that M-channel dysfunction in a background of abnormal excitability promotes seizure initiation and increases seizure severity, suggesting that increasing the level of the M-current may be of therapeutic benefit in individuals with generalized epilepsy. It has already been demonstrated in Phase II and Phase III clinical trials that the M-current enhancer retigabine has therapeutic benefit as an adjunctive therapy in patients with drug-resistant partial epilepsy (Bialer et al, 2009).

\section{Conclusions}

Our findings show that voltage-gated ion channel variants can modify the phenotype of a mouse model of GEFS+, and therefore suggest that coding, and possibly noncoding, variants in $S c n 2 a, S c n 8 a$, and Kcnq2 may influence clinical presentation and severity in patients with SCN1A mutations. The demonstrated genetic interactions between Scn1a, Scn2a, Scn8a, and $K c n q 2$, together with previous reports showing a genetic interaction between $S c n 2 a$ and Kcnq2 (Kearney et al, 2006) and Kcnal and Cacnala (Glasscock et al, 2007), support the notion that neuronal firing patterns are determined by the net sum of voltage-gated ion channel activity; hence, screening patients for mutations in a panel of selected ion channel genes may improve the utility of molecular diagnosis and risk assessment for guiding disease treatment. Traditional single gene screening approaches will probably be replaced by next-generation sequencing technologies, which will enable targeted re-sequencing of panels of selected genes, or whole exome analysis. Clinical diagnostic testing using next-generation sequencing of gene panels is already being applied to cardiology genetics (GeneDx, http://www.genedx.com/site/cardiology_genetic_testing_services). Similar molecular diagnostic approaches for epilepsy genetics are likely on the horizon.

\section{Research Highlights}

- Scnla $a^{R 1648 H}$ mice carry a human GEFS+ epilepsy mutation and have a mild phenotype

- A Scn2a mutation results in severe epilepsy and early lethality in $S c n 1 a^{R 1648 H}$ mice

- A subclinical Kcnq2 mutation exacerbates the phenotype of $S c n 1 a^{R 1648 H}$ mice

- A seizure-resistant $S c n 8 a$ mutation improves the phenotype of $S c n 1 a^{R 1648 H}$ mice Ion channel variants may contribute to clinical variability in monogenic epilepsy

\section{Supplementary Material}

Refer to Web version on PubMed Central for supplementary material. 


\section{Acknowledgments}

We thank India Reddy and Alison Miller for technical assistance and Cheryl Strauss for editorial assistance. This work was supported by the National Institutes of Health [R01NS053792 to JK, R01NS065187 to AE, and T32NS07491 to NH].

\section{ABBREVIATIONS}

GEFS+ $\quad$ Generalized epilepsy with febrile seizures plus

GTCS Generalized tonic-clonic seizure

MJ Myoclonic jerk

ECoG Electrocorticogram

\section{References}

Arkwright PD, Laurie S, Super M, Pravica V, Schwarz MJ, Webb AK, Hutchinson IV. TGF-beta(1) genotype and accelerated decline in lung function of patients with cystic fibrosis. Thorax 2000;55:459-62. [PubMed: 10817792]

Bergren SK, Chen S, Galecki A, Kearney JA. Genetic modifiers affecting severity of epilepsy caused by mutation of sodium channel Scn2a. Mamm Genome 2005;16:683-90. [PubMed: 16245025]

Bialer M, Johannessen SI, Levy RH, Perucca E, Tomson T, White HS. Progress report on new antiepileptic drugs: a summary of the Ninth Eilat Conference (EILAT IX). Epilepsy Res 2009;83:143. [PubMed: 19008076]

Biervert C, Schroeder BC, Kubisch C, Berkovic SF, Propping P, Jentsch TJ, Steinlein OK. A potassium channel mutation in neonatal human epilepsy. Science 1998;279:403-6. [PubMed: 9430594]

Charlier C, Singh NA, Ryan SG, Lewis TB, Reus BE, Leach RJ, Leppert M. A pore mutation in a novel KQT-like potassium channel gene in an idiopathic epilepsy family. Nat Genet 1998;18:53-5. [PubMed: 9425900]

Cooper EC, Jan LY. M-channels: neurological diseases, neuromodulation, and drug development. Arch Neurol 2003;60:496-500. [PubMed: 12707061]

Delmas P, Brown DA. Pathways modulating neural KCNQ/M (Kv7) potassium channels. Nat Rev Neurosci 2005;6:850-62. [PubMed: 16261179]

Dick DJ, Boakes RJ, Candy JM, Harris JB, Cullen MJ. Cerebellar structure and function in the murine mutant “jolting”. J Neurol Sci 1986;76:255-67. [PubMed: 3794752]

Drumm ML, Collins FS. Molecular biology of cystic fibrosis. Mol Genet Med 1993;3:33-68. [PubMed: 7693108]

Escayg A, MacDonald BT, Meisler MH, Baulac S, Huberfeld G, An-Gourfinkel I, et al. Mutations of SCN1A, encoding a neuronal sodium channel, in two families with GEFS+2. Nat Genet 2000;24:343-5. [PubMed: 10742094]

Fujiwara T. Clinical spectrum of mutations in SCN1A gene: severe myoclonic epilepsy in infancy and related epilepsies. Epilepsy Res 2006;70 (Suppl 1):S223-30. [PubMed: 16806826]

Glasscock E, Qian J, Yoo JW, Noebels JL. Masking epilepsy by combining two epilepsy genes. Nat Neurosci 2007;10:1554-8. [PubMed: 17982453]

Greenberg DA, Pal DK. The state of the art in the genetic analysis of the epilepsies. Curr Neurol Neurosci Rep 2007;7:320-8. [PubMed: 17618539]

Heron SE, Scheffer IE, Berkovic SF, Dibbens LM, Mulley JC. Channelopathies in idiopathic epilepsy. Neurotherapeutics 2007;4:295-304. [PubMed: 17395140]

Howe KL, Wang A, Hunter MM, Stanton BA, McKay DM. TGFbeta down-regulation of the CFTR: a means to limit epithelial chloride secretion. Exp Cell Res 2004;298:473-84. [PubMed: 15265695] 
Kearney JA, Plummer NW, Smith MR, Kapur J, Cummins TR, Waxman SG, et al. A gain-of-function mutation in the sodium channel gene $S c n 2$ a results in seizures and behavioral abnormalities. Neuroscience 2001;102:307-17. [PubMed: 11166117]

Kearney JA, Yang Y, Beyer B, Bergren SK, Claes L, Dejonghe P, Frankel WN. Severe epilepsy resulting from genetic interaction between Scn2a and Kcnq2. Hum Mol Genet 2006;15:1043-8. [PubMed: 16464983]

Kohrman DC, Smith MR, Goldin AL, Harris J, Meisler MH. A missense mutation in the sodium channel Scn8a is responsible for cerebellar ataxia in the mouse mutant jolting. J Neurosci 1996;16:5993-9. [PubMed: 8815882]

Martin MS, Dutt K, Papale LA, Dube CM, Dutton SB, de Haan G, et al. Altered function of the SCN1A voltage-gated sodium channel leads to GABAergic interneuron abnormalities. J Biol Chem 2010;285:9823-34. [PubMed: 20100831]

Martin MS, Tang B, Papale LA, Yu FH, Catterall WA, Escayg A. The voltage-gated sodium channel Scn8a is a genetic modifier of severe myoclonic epilepsy of infancy. Hum Mol Genet 2007;16:2892-9. [PubMed: 17881658]

Meisler MH, Kearney JA. Sodium channel mutations in epilepsy and other neurological disorders. J Clin Invest 2005;115:2010-7. [PubMed: 16075041]

Ogiwara I, Miyamoto H, Morita N, Atapour N, Mazaki E, Inoue I, et al. Na(v)1.1 localizes to axons of parvalbumin-positive inhibitory interneurons: a circuit basis for epileptic seizures in mice carrying an Scn1a gene mutation. J Neurosci 2007;27:5903-14. [PubMed: 17537961]

Otto JF, Yang Y, Frankel WN, White HS, Wilcox KS. A spontaneous mutation involving Kcnq2 (Kv7.2) reduces M-current density and spike frequency adaptation in mouse CA1 neurons. $\mathbf{J}$ Neurosci 2006;26:2053-9. [PubMed: 16481438]

Papale LA, Beyer B, Jones JM, Sharkey LM, Tufik S, Epstein M, et al. Heterozygous mutations of the voltage-gated sodium channel SCN8A are associated with spike-wave discharges and absence epilepsy in mice. Hum Mol Genet 2009;18:1633-41. [PubMed: 19254928]

Riordan JR, Rommens JM, Kerem B, Alon N, Rozmahel R, Grzelczak Z, et al. Identification of the cystic fibrosis gene: cloning and characterization of complementary DNA. Science 1989;245:1066-73. [PubMed: 2475911]

Sidman RL, Cowen JS, Eicher EM. Inherited muscle and nerve diseases in mice: a tabulation with commentary. Ann N Y Acad Sci 1979;317:497-505. [PubMed: 289327]

Singh NA, Charlier C, Stauffer D, DuPont BR, Leach RJ, Melis R, et al. A novel potassium channel gene, KCNQ2, is mutated in an inherited epilepsy of newborns. Nat Genet 1998;18:25-9. [PubMed: 9425895]

Singh NA, Otto JF, Dahle EJ, Pappas C, Leslie JD, Vilaythong A, et al. Mouse models of human KCNQ2 and KCNQ3 mutations for benign familial neonatal convulsions show seizures and neuronal plasticity without synaptic reorganization. J Physiol 2008;586:3405-23. [PubMed: 18483067]

Singh R, Andermann E, Whitehouse WP, Harvey AS, Keene DL, Seni MH, et al. Severe myoclonic epilepsy of infancy: extended spectrum of GEFS+? Epilepsia 2001;42:837-44. [PubMed: $11488881]$

Sugawara T, Tsurubuchi Y, Agarwala KL, Ito M, Fukuma G, Mazaki-Miyazaki E, et al. A missense mutation of the $\mathrm{Na}+$ channel alpha II subunit gene $\mathrm{Na}(\mathrm{v}) 1.2$ in a patient with febrile and afebrile seizures causes channel dysfunction. Proc Natl Acad Sci U S A 2001;98:6384-9. [PubMed: 11371648]

Tan NC, Mulley JC, Scheffer IE. Genetic dissection of the common epilepsies. Curr Opin Neurol 2006;19:157-63. [PubMed: 16538090]

Wallace RH, Wang DW, Singh R, Scheffer IE, George AL Jr, Phillips HA, et al. Febrile seizures and generalized epilepsy associated with a mutation in the Na+-channel beta1 subunit gene SCN1B. Nat Genet 1998;19:366-70. [PubMed: 9697698]

Yu FH, Mantegazza M, Westenbroek RE, Robbins CA, Kalume F, Burton KA, et al. Reduced sodium current in GABAergic interneurons in a mouse model of severe myoclonic epilepsy in infancy. Nat Neurosci 2006;9:1142-9. [PubMed: 16921370] 


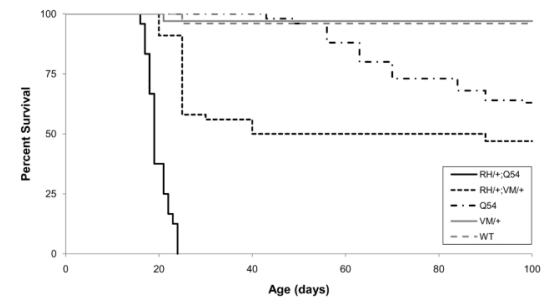

Figure 1.

Decreased survival of $S c n 1 a^{R H /+}$ mutants when combined with the $S c n 2 a^{Q 54}$ or $K c n q 2^{V M /+}$ alleles ( $n \geq 24$ per group). Abbreviations: RH, Scnla $a^{R H /+}$; Q54, Scn2a $a^{Q 44}$; VM, Kcnvq $2^{V M /+}$; WT, wildtype. 


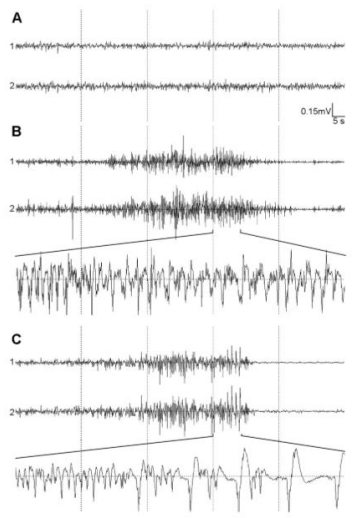

Figure 2.

$S c n 2 a$ and $K c n q 2$ alleles exacerbate the $S c n 1 a^{R H /+}$ phenotype. A. Normal ECoG pattern from $S c n l a^{R H /+}$ heterozygote. B. Representative ECoG recording from Scnla $a^{R H /+} ; S c n 2 a^{Q 54}$ double mutant during an ictal episode. C. Representative ECoG recording from $S c n l a^{R H /+} ; K c n q 2^{V M /+}$ double heterozygote during an ictal episode. Channel 1 , recording from right posterior to left posterior; Channel 2, recording from right anterior to left posterior. 


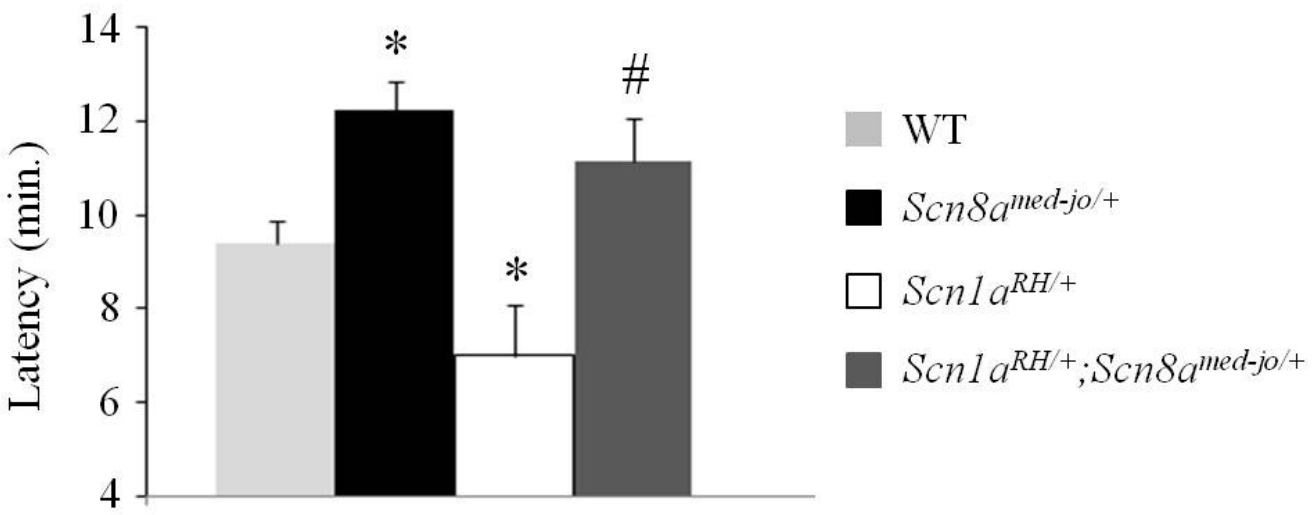

Figure 3.

Restoration of normal thresholds to flurothyl-induced seizures in $S c n l a^{R H /+}$ mutants. Average latency in minutes to the GTCS is shown. Light grey bar, WT; black bar, $S c n 8 a^{m e d-j o /+}$; white bar, Scnla ${ }^{R H /+}$; dark grey bar, Scnla $a^{R H /+} ; S c n 8 a^{\text {med-jo/+}} ; n=9-10$ per group. Error bars represent SEM. * indicates $P<0.05$ compared with WT littermates. \# indicates $P<0.001$ compared with $S c n l a^{R H /+}$ mutants; one-way ANOVA followed by Fisher's post hoc test. 


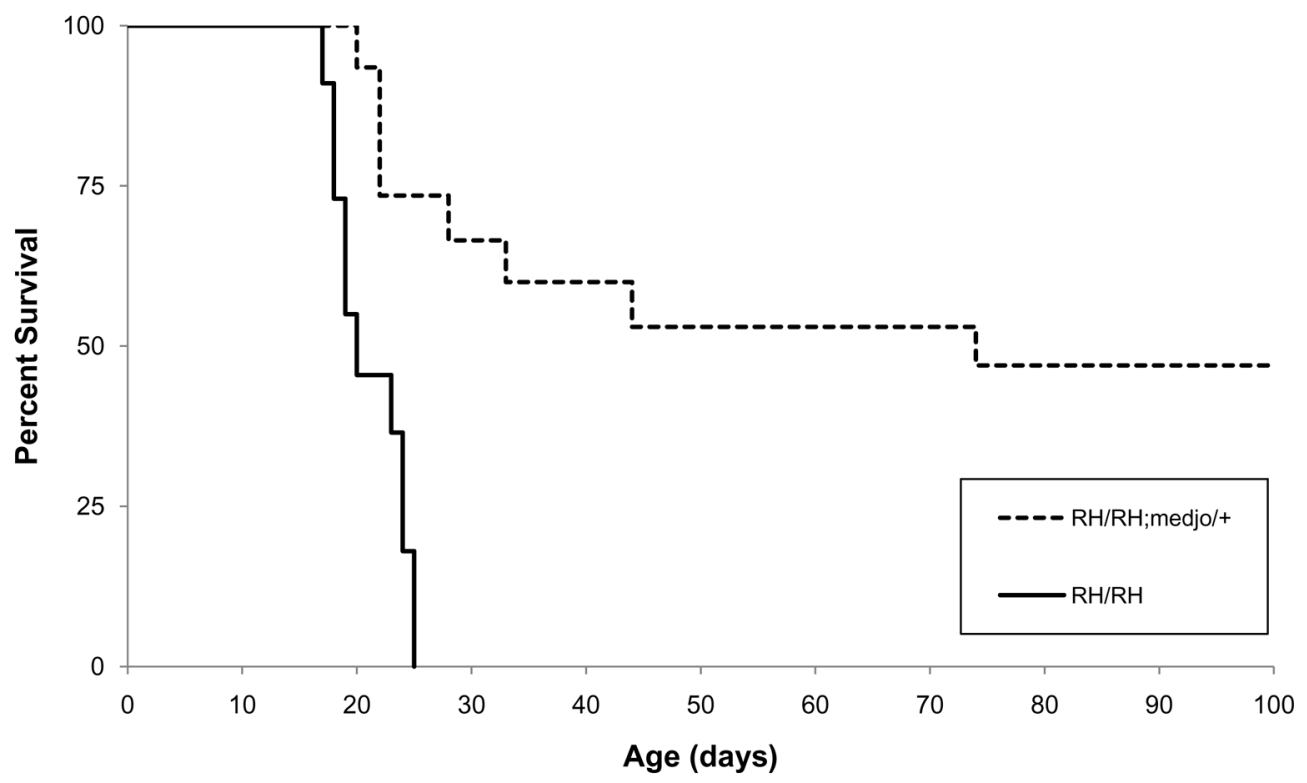

Figure 4.

Improved survival of $S c n 1 a^{R H / R H}$ mutants with the $S c n 8 a^{\text {med-jo/+ }}$ allele $(n=11-16$ per group). 


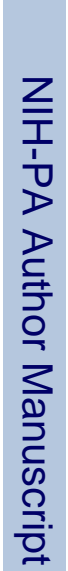

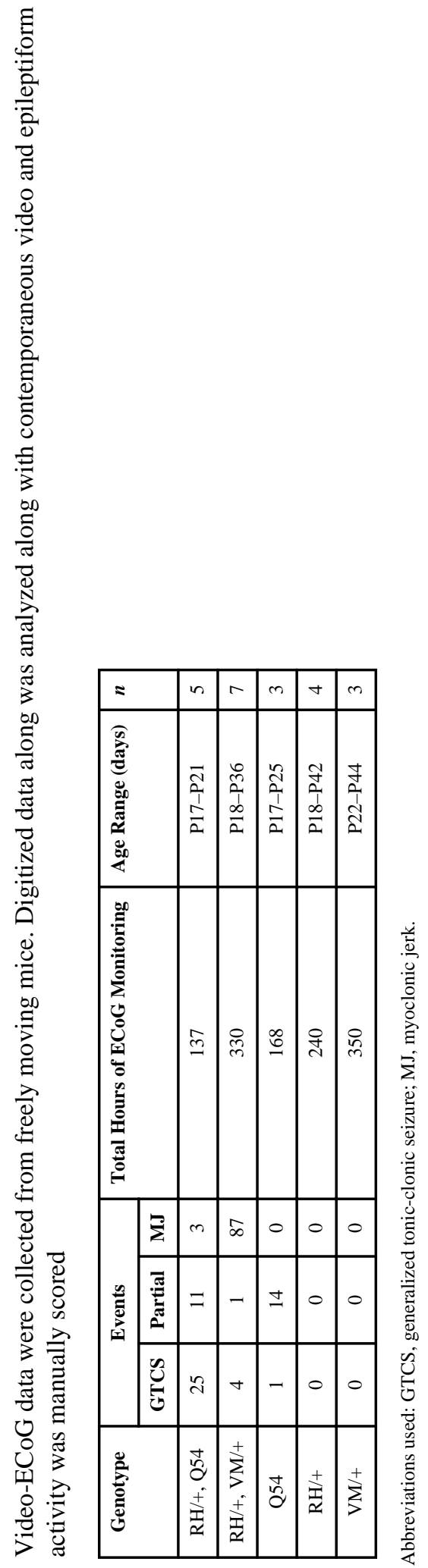

Neurobiol Dis. Author manuscript; available in PMC 2012 March 1. 